\title{
Mirando 25 Miradas. Una caja de herramientas para el análisis audiovisual
}

Mirando 25 Miradas. Análisis Sociosemiótico de los Cortos del Bicentenario

María Sol Baliosian

Escuela de Ciencias de la Información.

Facultad de Derecho y Ciencias Sociales,

Universidad Nacional de Córdoba

En el año 20Io, y con motivo de la celebración de los 200 años de la Revolución de Mayo, la por entonces Secretaría - hoy Ministerio- de Cultura de la Presidencia de la Nación convocó a 25 reconocidos artistas del medio audiovisual argentino para crear contenidos que tuvieran como disparador común la conmemoración de esa fecha patria.

Así nació 25 Miradas - 200 Minutos, un texto audiovisual compuesto por 25 cortos, de 8 minutos de duración cada uno, de diferentes directores. Los mismos narran diversas historias contadas desde múltiples perspectivas pero que comparten una misma temática: el Bicentenario de la Revolución de Mayo. De este modo, ofrecen 200 minutos de material audiovisual para repen- sar a la Argentina y los argentinos a 200 años de la gestación de su independencia.

Este material fue proyectado en diferentes salas del país, distribuido en soporte de DVD y a través de sitos en Internet de forma gratuita. Es de esta manera que los cortos se ponen en circulación y llegan al GEI (Grupo de Estudios de la Imagen de la Universidad Nacional de Córdoba). Este último, consciente de la particularidad de esa producción y motivado por ella, decide —en el año 20I2- enfocar sus actividades de investigación en pos del análisis sociosemiótico de estos discursos fílmicos, lo cual dio nacimiento a Mirando 25 Miradas. Análisis Sociosemiótico de los cortos del Bicentenario, libro que se propone reseñar el presente artículo. 
Desde sus páginas, la investigación propone «Pensar sobre nuestra historia y nuestra identidad, pensar con/a través de las imágenes, en la sociedad que las produce y de la que formamos parte». Así, Mirando 25 Miradas se interpreta a sí mismo y guía a sus lectores a través de un recorrido que invita a la búsqueda y a la apropiación de herramientas para el análisis de la imagen en movimiento.

En primera instancia, a partir de una breve pero exhaustiva introducción, expone el contexto sociohistórico en el cual surgen los textos audiovisuales objeto de análisis del libro —ya mencionados en el inicio del presente artículo-, pero también las condiciones de producción que hacen posible la propia publicación.

Cuenta que nació como proyecto en el año 2012 y tiene como compiladores a la Dra. Corina Ilardo y al Mgter. Diego Moreiras. Fue publicado en el mes de julio de 20I4, con el apoyo de la editorial del cepia (Centro de Producción e Investigación en Artes), perteneciente a la Universidad Nacional de Córdoba.

En un segundo momento, la Dra. Ilardo explica de manera sencilla y a la vez enriquecedora el marco teórico-metodológico a partir del cual toma cuerpo la investigación. Es así que, por un lado, pone al tanto al lector experto respecto de cuáles son los parámetros a partir de los que se llevará a cabo el análisis de los cortos y, por otro-por la forma en la que se presenta-, sirve como una pri- mera aproximación a los conceptos para quienes éste es su primer acercamiento al mundo de la semiótica y el análisis audiovisual.

En las páginas posteriores tienen lugar los análisis propiamente dichos. Veinticuatro escritores se apropian, en parejas o de forma individual, de los diferentes cortos, y es así que puede leerse un artículo por cada pieza audiovisual.

De este modo, se van aprehendiendo en su funcionamiento las diferentes herramientas evocadas en el apartado metodológico y se van actualizando otras que los autores creen necesarias debido a las particularidades de cada texto.

En cuanto a lo que comparten, queda planteada la base de la teoría sociosemiótica de Eliseo Verón. Partiendo de esta perspectiva, un texto/discurso no encuentra su sentido en sí mismo, sino que es producto de un trabajo efectuado en el marco de la semiosis social, conformada por una red de procesos de producción de sentido.

Por su parte, estos procesos de producción de sentido dejan huellas en los textos/discursos y es a partir de la recuperación de tales huellas que puede llegar a indagarse sobre tales procesos. Los textos no son otra cosa que representaciones de la realidad, una construcción del mundo —no su reflejo-y los cortos del bicentenario serían entonces representaciones elaboradas del mundo en las cuales se puede identificar huellas de un proceso 
productivo, que permite responder sobre otras cuestiones.

En sintonía con lo expuesto anteriormente, Mirando 25 Miradas adhiere a la propuesta metodológica de Eliseo Verón que, siguiendo a Émile Benveniste, plantea la necesidad de separar el análisis en dos momentos: el análisis del enunciado (aquello que se dice) y el análisis de la enunciación (los modos del decir).

Así se presentan los artículos referidos a cada corto. Ordenados de acuerdo con el esquema de aparición del dvd original y con sus variaciones de estilo a cargo de cada autor, es posible reconocer en cada uno de ellos las especificaciones pertinentes respecto del enunciado y de la enunciación.

En tanto enunciado, propone como elementos fundamentales a tener en cuenta el tratamiento que el relato hace del tiempo y los espacios, la caracterización y los roles de los personajes, la particularidad del esquema narrativo y las implicancias de sentido que las diferentes conjugaciones de estos elementos generan. En este sentido, se toman las contribuciones al campo de autores como André Gaudreault y François Jost, Francesco Casetti y Federico Di Chio en lo concerniente al análisis del espacio y el tiempo. Mientras que para el análisis de los personajes se toman como base los aportes de Edemetrio Diez Puertas -en tanto caracterización y rol-y las consideraciones de Algirdas J. Greimas para observar su función en el esquema narrativo.

En cuanto a la enunciación, se hace hincapié en la construcción de las dos grandes figuras de la enunciación propuestas por Eliseo Verón: enunciador y destinatario. Para analizar cómo estas se presentan en los diferentes cortos, se propone prestar atención no sólo a los elementos lingüísticos sino también al uso de las cámaras, los planos, las secuencias, el sonido, los silencios; observando los modos en que los cortos estructuran sus relatos y las estrategias que ponen en juego en pos de contar la historia.

Finalmente, una vez reunidos estos elementos, se puede apreciar al final de cada artículo una conclusión enfocada en los efectos de sentido que implican las diferentes configuraciones de las variables analizadas, tanto en enunciado y enunciación como en su conjunto.

De esta manera, teniendo como soporte este modelo de análisis pero no atados a él, los autores de Mirando 25 Miradas, van abriéndose paso y desentrañado los sentidos de las diferentes propuestas a través de sus artículos. Cada escritor va atendiendo las necesidades de su corto particular, agregando herramientas propuestas por distintos autores para el análisis de diversas estrategias narrativas.

Sobre la misma base teórico-metodológica, se ponen bajo la lupa producciones tan heterogéneas que van desde un corto con clara carga humorística, dirigido por 
Néstor Montalbano y protagonizado por Diego Capusotto - Chasqui-a otro de notable inclinación metafórica y dramática, creación del director Víctor Laplace, Ser uitil hoy.

El libro encuentra su final con un trabajo de análisis realizado en forma grupal por todo el equipo. Luego del recorrido efectuado por los artículos resulta este último apartado como una invitación a los lectores a sumarse a un análisis conjunto para poner en juego las herramientas aprehendidas en las páginas anteriores.

Mirando 25 Miradas es un manual práctico forjado con ejemplos para el inicio y ejercicio en el análisis de piezas audiovisuales. No sólo ofrece los resultados de una investigación, sino también abre ventanas para apreciar los procesos mediante los cuales se llega a ellos.
Además, proporciona la posibilidad de acercarse de manera privilegiada al objeto de estudio - los cortos - ya que cada libro se entrega acompañado de un DVD que los reúne.

Tal como señala en su Introducción, se propone brindar herramientas para el análisis y atender a las cuestiones especificas de este caso en particular, su coyuntura histórica y sus implicancias de sentido. Cumple así con sus objetivos de investigación y formación.

Por último, es importante, destacar que contribuye al campo de la formación de formadores. Por las características actuales y digitales del material analizado, resulta un libro interesante para llevar al aula, actividad prevista por el Grupo de Estudios sobre la Imagen como experiencia de extensión en los meses venideros. 